\title{
Study of Informative Advertising Competition Model in Duopolistic Market with Relative Profit Object
}

\author{
Jiao Lu \\ School of Management, Jinan University, Guangzhou, China \\ Email: lujiaolucy@126.com
}

How to cite this paper: Lu, J. (2017) Study of Informative Advertising Competition Model in Duopolistic Market with Relative Profit Object. Journal of Service Science and Management, 10, 105-111. https://doi.org/10.4236/jssm.2017.102009

Received: March 2, 2017

Accepted: April 10, 2017

Published: April 13, 2017

Copyright $\odot 2017$ by author and Scientific Research Publishing Inc. This work is licensed under the Creative Commons Attribution International License (CC BY 4.0).

http://creativecommons.org/licenses/by/4.0/ (c) (i) Open Access

\begin{abstract}
To study how the relative profit object influences duopolistic retailers' advertising decisions, this paper adds the relative profit object on the Hotelling Model to study its influence on advertising decisions. Through the calculation and analysis of the advertising competition model, we found that the balanced advertising level and product price is positively related to product differentiation level. The relationship between balanced profit and product differentiation level is related to the range of each variable. The balanced product price is positively related to advertising cost, while the balanced advertising level and profit is negatively related to advertising cost. The balanced product price, advertising level and profit are negatively related to relative profit ratio. Commonly, the higher the relative object ratio, the advertising level should be higher. This paper gets the opposite conclusion. Through analysis and discussion, we found that this is mainly influenced by the advertising cost level. As in this paper the advertising cost level is restricted to be high, enterprises will choose to raise price for more profit and lower advertising level to reduce cost while the relative profit ratio increases.
\end{abstract}

\section{Keywords}

Relative Profit, Advertising Competition, Pricing Competition, Duopoly Competition

\section{Introduction}

In the increasingly competitive market nowadays, advertising gradually becomes a significant factor that influences enterprise sales volume. In the last two to three decades, advertising is becoming more important for products with the development of economy. Various industries choose advertising to promote brand or to 
establish brand awareness for products, so as to attract consumers to the largest extend. Therefore, to make the proper advertising decision in the fast-changing market becomes a major task for enterprises. The study of supply chain advertising decision has great practical significance.

Through reading papers on advertising competition, we found that the current studies on supply chain advertising competition are almost based on the absolute profit object. But in reality, enterprises focus not only on their own profit, but also competitors' profit, which is to say that enterprises truly care about the combination of their own profit and competitors' profit. Most papers of this field focus on absolute profit. Bin Liu (2013) established a cooperation model to evaluate the advertising efficiency in absolute profit object [1]. Jinfeng (2013) used a cooperation game theory model to study the optimal strategy [2]. Some researchers have applied relative profit to study various phenomena. Boone (2008) applied a newly model called RPD (relative profit difference) to study enterprise competition in certain industries and further proved the robustness by empirical study [3].

Tirole (1988) explained in The Theory of Industrial Organization that even though expected profit maximization is the assumption for many economic theories, the common feeling is that managers in firms have different objectives like firm scale and salary maximization [4]. Similarly, we believe that the managers' advertising decisions are affected by competitors' advertising and profit.

Many cases in the real world have proven this theory. For example, the advertising competition between Jiaduobao and Wanglaoji has clearly shown that Jiaduobao has the incentive to exceed its competitor Wanglaoji both in profit and sales in their competitions. In 2012, Jiaduobao named the variety Voice of China in Zhejiang TV with 60,000,000 yuan (Netease, 2012). With the hot broadcast of the variety, sales of Wanglaoji increased dramatically, the brand got a well advertising effect. In 2013, Jiaduobao asserted that it would spend 200,000,000 yuan to name the second season of the Voice of China (Netease, 2013). Meanwhile, its major competitor Wanglaoji claimed to name the variety Open the Door for Happiness in CCTV and other varieties on Hunan TV. As for the advertising slogan, Jiaduobao chose "Herbal Tea, Jiaduobao goes ahead", "Escape from excessive internal heat, drink Jiaduobao", while Wanglaoji chose, "Escape from excessive internal heat, drink Wanglaoji” as its slogan. We can clearly see that both firms take each other into consideration in their slogan. Similar competition abounds in various industries like household appliance and online shopping. Firms take competitors into consideration in making strategies in their advertising campaign. Therefore, it is of much importance in analyzing enterprises' decision process under relative profit object in advertising competition. Zonglai Koua \& Min Zhou (2015) established a Hotelling competition model based on relative profit and found that the balanced result is greatly influenced by relative profit level [5].

Considering the situation, this paper adds the relative profit function in the traditional supply chain advertising competition model to study its influence on 
advertising decision. That is to say, we consider firms to be irrational, holding the objective of relative profit. Based on relative profit function, we establish an advertising competition model. This research fits more into real world and shows significant explanation and direction to enterprises.

\section{Model Description}

Assuming there exists an oligopolistic market, retailer $i$ and retailer $j$ sell product $i$ and product $j$ respectively in this market. Customers can only know about product information via advertising. Say that the advertisings are sending true information about products. Both retailers compete by pricing and advertising and choose to maximize their relative profit.

According to previous studies, the sales $q_{i}$ of retailer $i$ can be calculated by $q_{i}=\phi_{i}\left[\phi_{j}\left(\frac{t+p_{j}-p_{i}}{2 t}\right)+1-\phi_{j}\right](i, j=1,2)$, where $t(t>0)$ stands for customer's unit cost in buying a product, also called preference cost, $p_{i}$ and $p_{j}$ stands for the price of product $i$ and $j, \phi_{i}$ and $\phi_{j}$ stands for the advertising level of product $i$ and $j$ (Hamilton, 2009) [6].

The absolute profit function of retailer $i$ can be calculated below.

$$
\pi_{i}=p_{i} \phi_{i}\left[\phi_{j}\left(\frac{t+p_{j}-p_{i}}{2 t}\right)+1-\phi_{j}\right]-\alpha \phi_{i}^{2}(i=1,2)
$$

The relative profit function of retailer $i$ thus can be calculated below.

$$
\begin{aligned}
U_{i}= & p_{i} \phi_{i}\left[\phi_{j}\left(\frac{t+p_{j}-p_{i}}{2 t}\right)+1-\phi_{j}\right]-\alpha \phi_{i}^{2} \\
& -\beta\left\{p_{j} \phi_{j}\left[\phi_{i}\left(\frac{t+p_{i}-p_{j}}{2 t}\right)+1-\phi_{i}\right]-\alpha \phi_{j}^{2}\right\} \\
& (i, j=1,2 \text { and } i \neq j)
\end{aligned}
$$

The first derivatives of $U_{i}$ versus $p_{i}$ and $\phi_{i}$, equaling to 0 . We can get the following results.

$$
\begin{gathered}
1-\frac{\phi}{2}-\frac{p \phi(1+\beta)}{2 t}=0 \\
p\left(1-\frac{\phi}{2}\right)+\frac{\beta p \phi}{2}-2 \alpha \phi=0
\end{gathered}
$$

The first derivative of $U_{i}$ versus $\phi_{i}$ can be interpreted that the unit advertising increasing brings the retailer absolute profit increasing $p\left(1-\frac{\phi}{2}\right)$ and brings the retailer relative profit increasing $\frac{\beta p \phi}{2}$, while binging advertising cost $2 \alpha \phi$.

Solving the two functions simultaneously, the following is obtained.

$$
\phi^{e}=\frac{4 \sqrt{t}}{\sqrt{t}(2-\beta)+\sqrt{t \beta^{2}+16 \alpha(1+\beta)}}
$$




$$
p^{e}=\frac{-t \beta+\sqrt{t\left(t \beta^{2}+16 \alpha(1+\beta)\right)}}{2(1+\beta)}
$$

From $0<\phi^{e}<1$, we calculate that $t<4 \alpha$ should be satisfied. We can further have the retailer profit.

$$
\pi^{e}=\frac{4 t\left(t \beta^{2}+4 \alpha(1+\beta)-\beta \sqrt{t^{2} \beta^{2}+16 \alpha t(1+\beta)}\right)}{(1+\beta)\left(\sqrt{t}(2-\beta)+\sqrt{t \beta^{2}+16 \alpha(1+\beta)}\right)^{2}}
$$

\section{Model Analysis}

In the beginning, to investigate the influence of product differentiation on the balanced equilibrium, we calculate the first derivatives of balanced price and advertising level versus product differentiation and analyze it, obtaining the result below.

$$
\begin{aligned}
& \text { Proposition } 1 \frac{\partial p^{e}}{\partial t}>0, \frac{\partial \phi^{e}}{\partial t}>0 \\
& t<f(\alpha, \beta), \frac{\partial \pi^{e}}{\partial t}>0 \\
& t>f(\alpha, \beta), \frac{\partial \pi^{e}}{\partial t}<0 \\
& f(\alpha, \beta)=\frac{4(\alpha+2 \alpha \beta)}{(1-\beta) \beta}-4 \sqrt{\frac{4 \alpha^{2}+5 \alpha^{2} \beta}{(-1+\beta)^{2} \beta}} .
\end{aligned}
$$

From proposition 1 we see that the balanced price and advertising level are positively related to product differentiation. This result is attributed by the customer category. Customers can be divided into two categories, the first only receive advertising from one retailer, the second from two retailers. With the increasing of product differentiation, unit transportation cost for customer increases, therefore the competition for the second category becomes harder. Retailers will pay more attention to the first category. To improve the number of the first category, retailers will further improve the advertising level; meanwhile, to implement the advertising cost, retailers will raise product price.

Proposition $2 \frac{\partial \phi^{e}}{\partial \alpha}<0, \frac{\partial p^{e}}{\partial \alpha}>0, \frac{\partial \pi^{e}}{\partial \alpha}>0$.

From proposition 2, the balanced advertising level and the profit is negatively related to advertising cost, the balanced price is positively related to advertising cost. This proposition can be explained in the following ways. The direct effect of advertising cost increasing is retailer decreasing advertising level. The indirect effect is the proportion of customer category 1 increasing $\left(\frac{\phi_{i}\left(1-\phi_{j}\right)}{\phi_{i} \phi_{j}}=\frac{1}{\phi_{j}}-1\right)$. As this category surely will buy the product, retailers choose to raise product price to gain more profit. This result conforms to the previous research by Chinese scholars Shuhong Peng and Xianyu Wang (2005) on the retailers' competi- 
tion of products with vertical differentiation.

In the end, to investigate relative profit level influence on the balanced result, we calculate the first derivative on $\beta$, we can obtain the following result.

Proposition $3 \frac{\partial \phi^{e}}{\partial \beta}<0, \frac{\partial p^{e}}{\partial \beta}<0, \frac{\partial \pi^{e}}{\partial \beta}<0$.

From Proposition 3 , the more retailers pay attention to relative profit, the lower the balanced price, the balanced advertising level, the balanced profit. This proposition tells us the following truth. While retailers pay more attention to relative profit, they should compete more fiercely. However, the balanced advertising is negatively related to relative profit object level. Through analyzing, it is attributed by the assumption of $t<4 \alpha$, that is $\alpha>\frac{t}{4}$. It restricts the advertising cost in a relatively high level. Once the competition becomes fierce, the retailers could either choose price competition or advertising competition. As advertising cost is relatively high, retailers choose price competition. Meanwhile, to gain more profit, retailers will lower advertising level. To prove this, we assume that $\alpha<\frac{t}{4}$ and calculate that $\frac{\partial \phi}{\partial \beta}>0$. It means that while advertising cost is in a low level, retailers will choose to raise advertising level to face fierce competition. This further proves the previous analysis.

From this proposition, we found a shortage of the model, the advertising cost restriction of the model is severe. However, in the present situation, it could be relatively high or low, especially in the internet times. As a result, one of the significant ways to extend this model is to loosen its restriction.

\section{Numerical Examples}

To further illustrate the influence of each parameter on the balanced result, this part settles different values and calculates the balanced result. By investigating the paragraph, we can verify the propositions, see the following analysis.

From Figure 1 and Figure 2, we know that under relative profit object, $\alpha=1 / 2$, the balanced price and advertising level decreases with the increase of

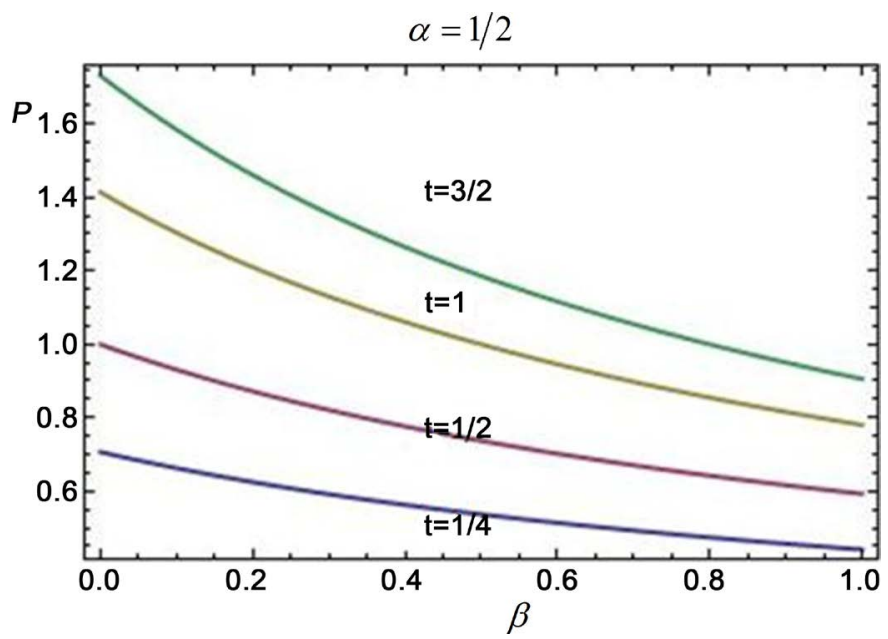

Figure 1. Balanced price curve when $\alpha=1 / 2$. 


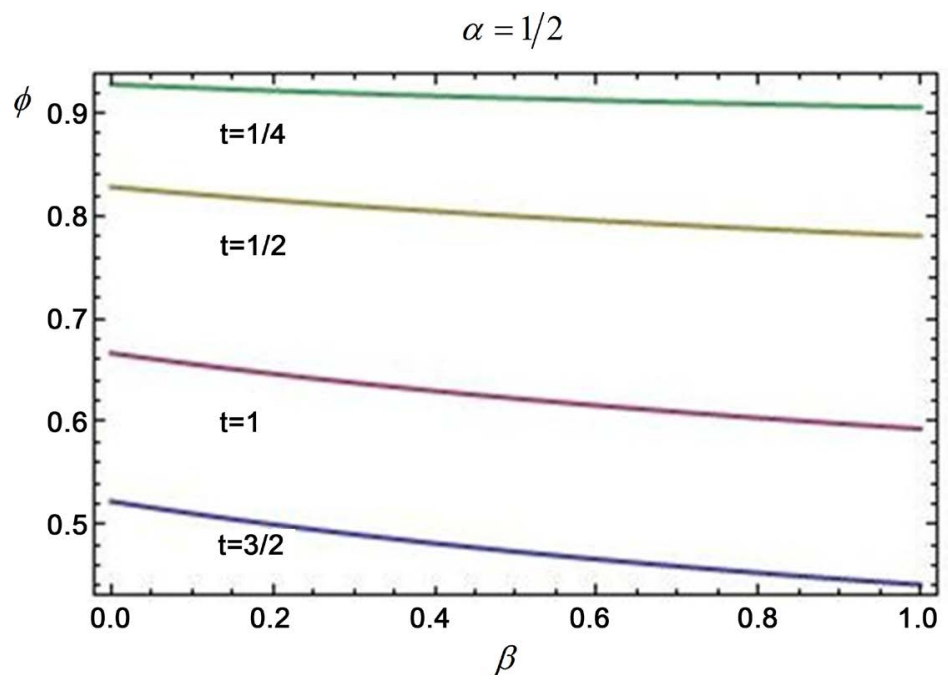

Figure 2. Balanced advertising curve when $\alpha=1 / 2$.

relative object level $\beta$. This is consistent with the previous proposition. Meanwhile, with the increase of transportation cost $t$, we can see that the balanced price and advertising level changes regularly. The balanced price is positively relatively related with product differentiation level $t$, the balanced advertising is negatively related with product differentiation level $t$.

\section{Conclusions}

Observing that the papers are all concerned with absolute profit object while the present life exists relative profit object, this paper adds relative profit object to the prevalent advertising competition model and establishes a duopolistic model to investigate the influence of relative profit object on the balanced result. By model calculating and numerical example, we find that under relative profit object, the balanced advertising and price is positively related to product differentiation. The balanced advertising is negatively related to advertising cost, the balanced price and profit are positively related to advertising cost. In the third part, we use a numerical example to examine the result. The diagrams verify the previous propositions.

Still, this paper is very limited and has some aspects to extend. This paper limits the advertising cost in a high level; we could further investigate the situation with a low advertising cost.

\section{References}

[1] Liu, B. (2013) Advertising in Asymmetric Competing Supply Chains. Production and Operations Management, 23, 1845-1858. https://doi.org/10.1111/poms.12090

[2] Yue, J.F., Austin, J., Huang, Z.M. and Chen, B.T. (2013) Pricing and Advertisement in a Manufacturer-Retailer Supply Chain. European Journal of Operational Research, 231, 492-450. https://doi.org/10.1016/j.ejor.2013.06.007

[3] Boone, J. (2008) A New Way to Measure Competition. The Economic Journal, 118, 1245-1261. https://doi.org/10.1111/j.1468-0297.2008.02168.x

[4] Tirole, J. (1988) The Theory of Industrial Organization. MIT Press, Cambridge. 
[5] Koua, Z.L. and Zhou, M. (2015) Hotelling's Competition with Relative Performance Evaluation. Economics Letters, 130, 69-71.

[6] Hamilton, S.F. (2009) Informative Advertising in Differentiated Oligopoly Markets. International Journal of Industrial Organization, 27, 60-69.

https://doi.org/10.1016/j.ijindorg.2008.04.002

Submit or recommend next manuscript to SCIRP and we will provide best service for you:

Accepting pre-submission inquiries through Email, Facebook, LinkedIn, Twitter, etc. A wide selection of journals (inclusive of 9 subjects, more than 200 journals)

Providing 24-hour high-quality service

User-friendly online submission system

Fair and swift peer-review system

Efficient typesetting and proofreading procedure

Display of the result of downloads and visits, as well as the number of cited articles Maximum dissemination of your research work

Submit your manuscript at: http://papersubmission.scirp.org/

Or contact jssm@scirp.org 